ISSN 1112-9867

http://www.jfas.info

\title{
EVALUATION OF THE EFFECT OF ADVANCED COAGULATION PROCESS TO OPTIMIZE THE REMOVAL OF NATURAL ORGANIC MATTER IN WATER (CASE STUDY: DRINKING WATER OF MASHHAD'S KARDEH DAM)
}

\author{
A. R. Mahmouei ${ }^{1}$, M. Arjmand ${ }^{1}$ and M. Rezaee $^{3}$ \\ ${ }^{1}$ Department of Civil Engineering, Bozorgmehr University of Qaenat, Iran \\ ${ }^{2}$ Department of Civil Engineering, University of Zabol, Iran
}

Published online: 05 June 2016

\begin{abstract}
Natural Organic Matter (NOM) is a non-uniform mixture of organic compounds that enter water after synthesis of plants, animals, etc. Among the organic matters in natural waters, humic substances which usually exist as solutions have allocated a major portion to themselves and in addition to giving taste, color and odor to the water, they can intervene in the oxidization and removal of heavy metals such as arsenic, iron and manganese. Also, the natural organic precursors of disinfection by-products have been recognized as toxic or carcinogenic substances.

The coagulation process is optimized as the most common system of water treatment in Iran for removing turbidity of water. This process is capable of removing the natural organic matter but the conditions for the removal of turbidity are constantly not identical with the optimum conditions for removing the NOM.
\end{abstract}

Author Correspondence, e-mail: rezvani@buqaen.ac.ir doi: http://dx.doi.org/10.4314/jfas.8vi2s.48 
Therefore, where NOM is the main pollutant, the traetment process should be optimized for removing NOM. Therefore, where NOM is the main pollutant, the traetment process should be optimized for removing NOM.

After doing the common treatment, the water of Kardeh dam of Mashhad is used as drinking water of the city of Mashhad. By doing the water analysis experiments, the amounts of natural organic matter in the exiting water from water treatment plant was observed at $5 \mathrm{mg} / \mathrm{l}$ which is much higher than the world standards of drinking water.

In this research the optimum conditions for the removal of NOM from drinking water of Kardeh dam have been examined. The experiments have been conducted at the laboratory scale and by Jar Test Device by different doses of two coagulants of alum and ferric chloride at various $\mathrm{pH}$ of water. It is concluded that these coagulation process by two coagulants remove NOM from drinking water and bring it to standards of US Environmental Protection Agency and World Health Organization.

Keywords: advanced coagulation; natural organic matter; drinking water; city of Mashhad.

\section{INTRODUCTION}

The surface waters always contain high values of organic and mineral matters resulting from cleaning the riverbeds, solution of matters, decomposition of leaves, algae and other microorganisms in the water way. Besides, drainage of sewage and hazardous pollutants such as residues of various types of organic materials used in agriculture to surface water decreases the efficiency of the conventional treatment processes for providing safe drinking water[5].

The presence of organic matters in the water resources has always been problematic for drinking water treatment plants. The most important of which include the role of such matters in transfer and concentration of different pollutants, planning the formation and microbial growth in water distribution systems and as a precursor in formation of dangerous by-products after chlorination[7].

There are two main methods in water treatment: 
- The conventional method: Pre-treatment operation, addition of chemicals, coagulation and flocculation, sedimentation, aeration, filtration and disinfection.

- Advanced methods of water treatment[5].

The conventional method of water treatment which is based on coagulation is optimized in Iran to reduce water turbidity and therefore, they do not have a good efficiency in reducing the organic matters. Thus, in a condition that the amount of turbidity is not great, the coagulation process can be optimized to remove the NOM.

Kardeh dam, located 40 kilometers from the city of Mashhad, is one of the resources of drinking water of the city and its suburbs. This water is available for the residents of this area after conventional treatment by the water treatment plant for the purpose of removing its turbidity and pathogens.

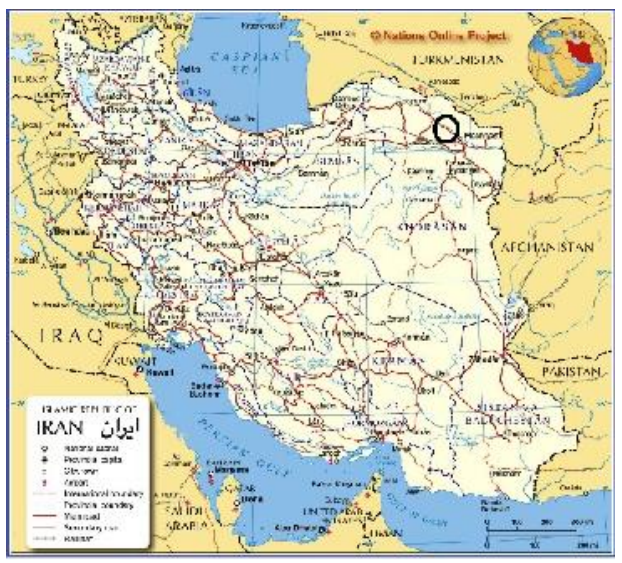

Fig.1. The location of the city of Mashhad and Kardeh Dam

By conducting the water analysis experiments, the amounts of natural organic matters in the water exiting from the water treatment plant was observed at $5 \mathrm{mg} / \mathrm{l}$ which is higher than world standards of drinking water. This research has examined the optimum conditions of NOM removal from drinking water of Kardeh Dam. The experiments have been conducted at the laboratory scale using Jar Test device through different doses of two coagulants of alum and ferric chloric and in different $\mathrm{pH}$ of water. 


\section{METHOD AND MATERIAL}

At first, the water exiting from the water treatment plant of Kardeh dam (the output of primary sedimentation basins) was examined and analyzed. Analysis of water to determine the amount of TOC present in it was done three times during summer (due to higher amount of TOC present compared to other seasons of the year). The specifications quality of the water of Karaj River is shown in Table 1. In all sampling, the effluent of the all water treatment plant units was performed simultaneously in order to determine their efficiency in TOC removal.

Table 1. Chemical analysis of Water in the effluent of Primary Sedimentation Ponds

\begin{tabular}{|c|c|c|c|c|c|c|c|}
\hline $\begin{array}{l}\text { Sample } \\
\text { Number }\end{array}$ & $\begin{array}{l}\text { Electrical } \\
\text { Conductivity } \\
(\mu s / \mathrm{cm})\end{array}$ & $\begin{array}{l}\text { Alkalinity } \\
(\mathrm{mg} / \mathrm{l} \text { as } \\
\left.\mathrm{caco}_{3}\right)\end{array}$ & $\begin{array}{l}\text { Hardness } \\
(\mathrm{mg} / \mathrm{l} \text { as } \\
\left.\operatorname{caco}_{3}\right)\end{array}$ & $\begin{array}{l}\text { TOC } \\
(\mathrm{mg} / \mathrm{l})\end{array}$ & $\begin{array}{c}\text { Turbidity } \\
\text { (Ftu) }\end{array}$ & $\begin{array}{l}\mathrm{p} \\
\mathrm{H}\end{array}$ & $\begin{array}{c}\text { Temperatu } \\
\text { re } \\
\left({ }^{o} C\right)\end{array}$ \\
\hline 1 & 345 & 144 & 180 & 4.8 & 7 & 7.5 & 22 \\
\hline 2 & 380 & 140 & 220 & 5.1 & 7 & 7.5 & 24 \\
\hline 3 & 480 & 147 & 196 & 5 & 8 & 7.4 & 25 \\
\hline
\end{tabular}

In order to remove the organic matters, all the beakers, the sampling bottles, glassware and blades used in Jar Testing were soaked for 24 hours in $20 \%$ sulfuric acid solution and then washed with water and finally rinsed with distilled water.

The method of Jar Test was as follows. After adding the ferric chloric or alum, rapid mixing was done for one minute with $120 \mathrm{rpm}$ and flocculation with $30 \mathrm{rpm}$ for 20 minutes. According to recommendations of US Environmental Protection Agency, at the end of the experiment the sample was set into a state of stasis for sedimentation for 30 minutes. During the course of the experiments $\mathrm{pH}$ was regulated by sulfuric acid $1 \mathrm{~N}$.

After Jar test, by means of a pipette in the depth of $4-5 \mathrm{~cm}$ of water surface, sampling was done. Due to lack of possibility of testing TOC in the water treatment plant of Kardeh dam of Mashhad, to preserve the samples, glass bottles of $250 \mathrm{ml}$ with frosted caps were used. Preservation of the 
samples before measuring TOC was conducted by making the $\mathrm{pH}$ reach to less than 2 and by using acid sulfuric. The instrument used for testing the concentration of total organic carbon in the studied samples was a German instrument of the model $\frac{\text { Uersion } 28 / 02-2000}{\text { Micro N/C TOC }}$. Measuring turbidity was done by turbidity-meter of Hach model.

\section{RESULT AND DISCUSSION}

At First, the effect of the two coagulants of alum and ferric chloride in the primary $\mathrm{pH}$ of water were examined. As it can be observed in figures 2 and 3, along with the increase in the dose of the coagulant, the amount of TOC decreases and the optimum dose of alum and ferric chloric in the removal of TOC and $\mathrm{pH}$ are 40 and $20 \mathrm{mg} / \mathrm{l}$ respectively.

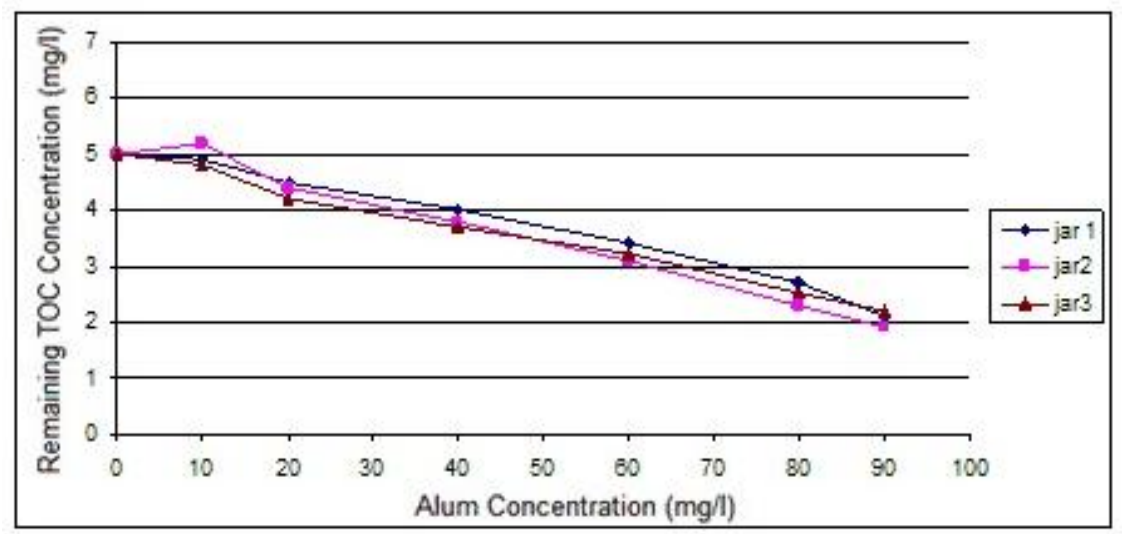

Fig.2. The remaining TOC concentration in different iterations with different doses of ferric chloric in the initial $\mathrm{pH}$ 


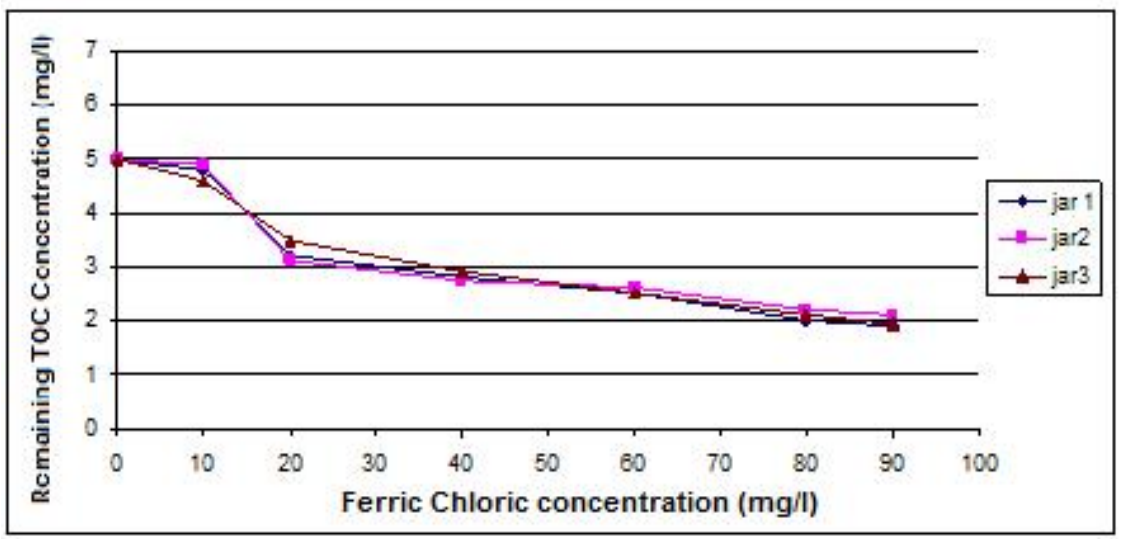

Fig.3. The concentration of remaining TOC in different iterations with different doses of ferric chloric in the initial $\mathrm{pH}$

By determining the optimum dose of two coagulants at the next stage with keeping the amount of optimum dose in a fix condition, the effect of $\mathrm{pH}$ change on the amount of TOC was examined. At the optimum obtained concentration at the previous stage for two coagulants of alum and ferric chloric under different $\mathrm{pH}$ levels, the range of optimum $\mathrm{pH}$ for two coagulants were 6-6/5 and 4/5-5 respectively.

As it can be observed in Figures 4 and 5 within a large range of $\mathrm{pH}$, two mentioned coagulants have suitable removal efficiency.

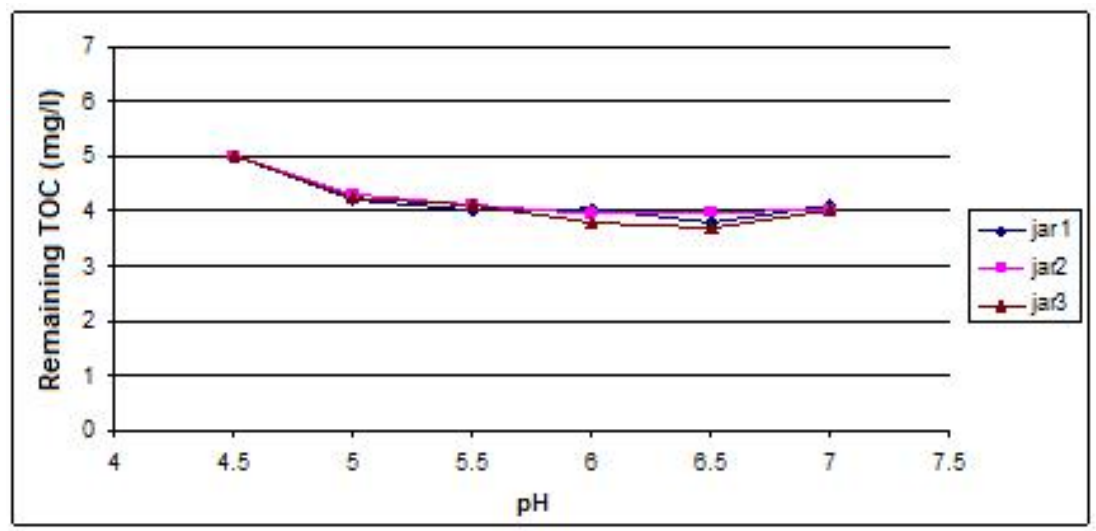

Fig.4. The remaining TOC concentrations in each iteration with fixed alum concentration and different $\mathrm{pH}$ 


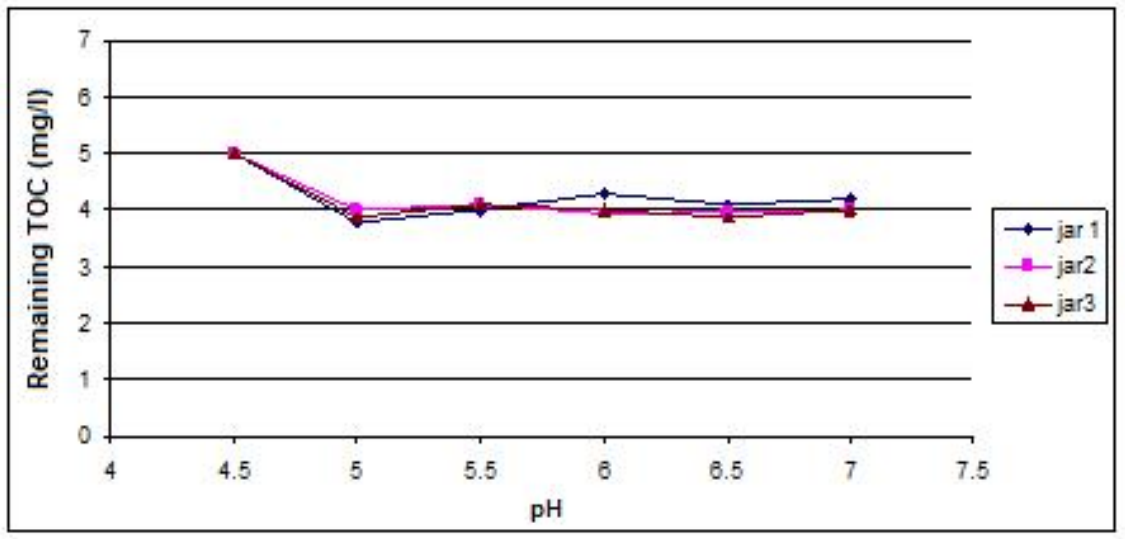

Fig.5. The remaining TOC concentration in each iteration with fixed concentration of ferric chloric and different $\mathrm{pH}$

At the next stage of the experiment, $\mathrm{pH}$ was considered constant (the amount of optimum $\mathrm{pH}$ ) and was examined under different doses of coagulant to remove TOC. As it can be observed, with the increase in the amount of alum and ferric chloric, respectively to $80 \mathrm{mg} / \mathrm{l}$ and $75 \mathrm{mg} / \mathrm{l}$, the concentration of the remaining TOC in water reaches to under $2 \mathrm{mg} / \mathrm{l}$ which is In accordance with the standard of the US Environmental Protection Agency and World Health Organization.

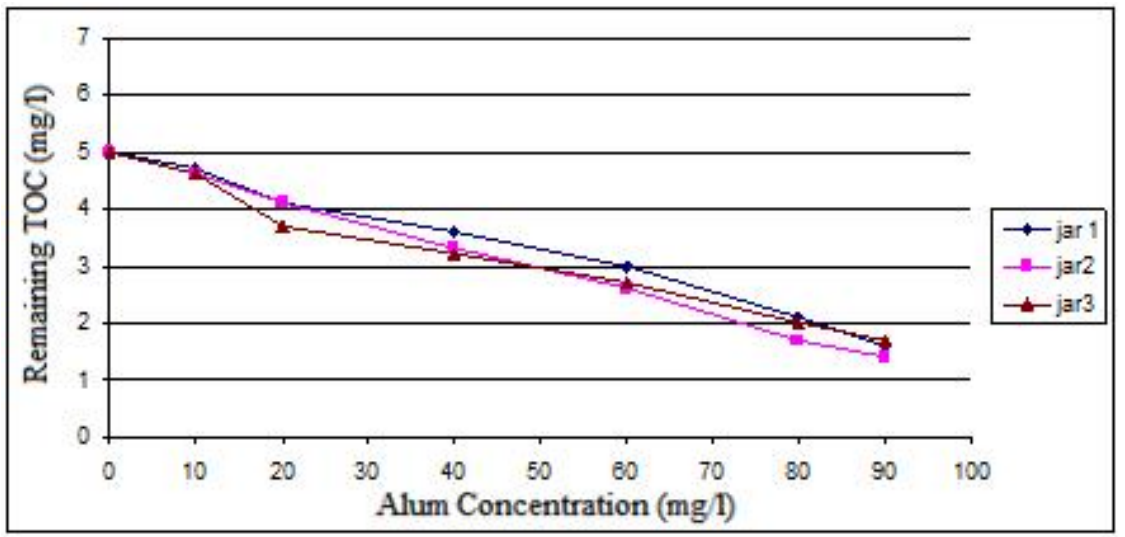

Fig.6. The remaining TOC concentration in each interation with different concentrations of alum and optimum $\mathrm{pH}$ level 


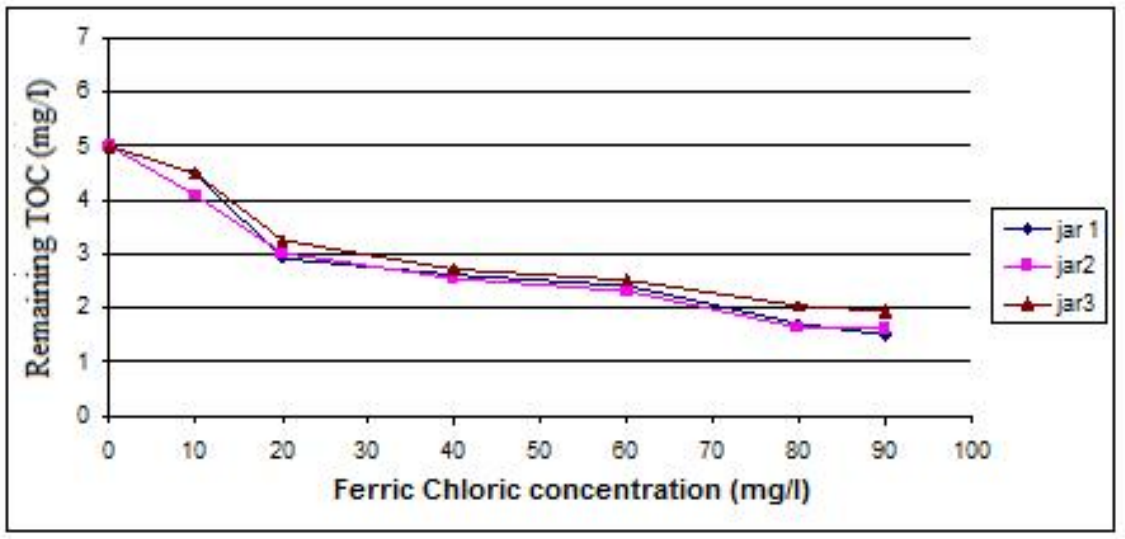

Fig.7. The remaining TOC concentration in each interation with different concentrations of ferric chloric and optimum $\mathrm{pH}$ level

\section{CONCLUSIONS}

Measuring the concentration of TOC output from the water treatment plant of Kardeh dam of Mashhad city indicates the poor performance of the conventional treatment process in removing TOC from raw water exiting the dam.

The reason of which could be optimization of the process of water treatment for reducing of turbidity.

Due to the high concentration of THMs and Halo acetic acids, the need for optimizing the water treatment process in removing TOC to the standard level of EPA and WHO is necessary.

The results from this paper and other similar studies show that controlling the $\mathrm{pH}$ level of coagulation process is one of the most important factors in removing TOC. The results of this study show the appropriate performance of alum and ferric chloric coagulants in removing TOC from drinking water of Kardeh dam. With respect to the fact that adding alum or ferric chloric to the water results in the reduction of water $\mathrm{pH}$ within the range of optimum performance of these two coagulants, therefore, TOC removal and optimal performance of the coagulants is not necessary to modifying $\mathrm{pH}$ level of raw water. 


\section{REFERENCES}

[1] Crittenden, J.C., Rhodes, T.R., Hand, D.W., Howe, K.J. and Tchobanoglous, G. Water Treatment: Principles and Design, 2nd edition, John Wiley \& Sons Inc, 2005.

[2] Enhanced coagulation and enhanced precipitative softening guidance manual, USEPA, Office of Water, Washington.D.C, 1999.

[3] Lauer, Wm., et. al., Chemical Feed Field Guide for Treatment Plant Operators, American Waterworks Association, 2008.

[4] National Recommended Water Quality Criteria, United States Environmental Protection Agency, National Recommended Water Quality Criteria, 2008.

[5] Rashidi, A. and Fazeli, M. (2001). Water treatment and the methods of improving its quality, Water and Power Industry University Publications, Tehran, Iran.

[6] Selcuk, H., et al. DBPs Formation and Toxicity Monitoring in Different Origin Water Treated by Ozone and Alum/PAC Coagulation, Desalination Journal, 2007, Amsterdam, Netherlands.

[7] Torabian, A., and Ghadim Khati, A. (2007). Design and operation of water treatment plans, Tehran University Press, Tehran, Iran.

[8] Water Quality and Treatment, McGraw-Hill, 5th edition, 1999.

\section{How to cite this article:}

Mahmouei A. R Arjmand M and Rezaee M. Evaluation of the effect of advanced coagulation process to optimize the removal of natural organic matter in water (Case study: drinking water of Mashhad's Kardeh dam). J. Fundam. Appl. Sci., 2016, 8(2S), 359-367. 